Figure:


C

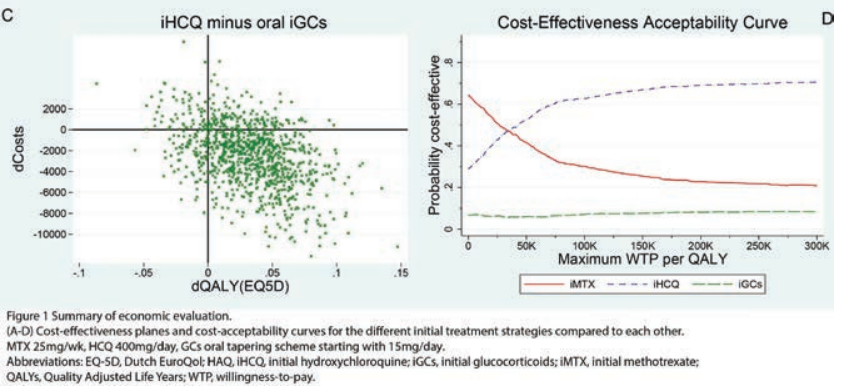

Disclosure of Interests: None declared

DOI: 10.1136/annrheumdis-2020-eular.1394

\section{OP0284 AN AGENT-BASED SIMULATION OF THE EFFECTS OF VARYING TIME TO TREATMENT WITH BIOLOGICAL AGENTS ON PATIENT HEALTH AND COST IN AXIAL SPONDYLOARTHRITIS USING NATIONAL REGISTER DATA}

A. Roach ${ }^{1}$, I. Scott ${ }^{2}$, G. Macfarlane ${ }^{3}$, G. T. Jones ${ }^{3}$, A. Macgregor4. ${ }^{1}$ University of East Anglia, Norwich, United Kingdom; ${ }^{2}$ Keele University, Keele, United Kingdom; ${ }^{3}$ University of Aberdeen, Aberdeen, United Kingdom; ${ }^{1}$ University of East Anglia, Norwich, United Kingdom

Background: Evaluating the long-term impacts of healthcare policies on patient's health and treatment costs for people with axial spondyloarthritis (axSpA) is challenging due to its chronic nature, and the variation in individual patient journeys post-diagnosis. Agent-based simulations are a novel approach to interrogating this complexity, and allow the consequences of different policy scenarios on outcomes to be explored.

Objectives:

1. Develop and validate an agent-based simulation of the UK axial spondyloarthritis healthcare system, using real-world data.

2. Interrogate the effects of earlier biologic treatment on costs and patient outcomes.

Methods: Anonymised data were obtained from the UK National Early Inflammatory Arthritis Audit, and BSR Biologics Register (BSRBR-AS). This provided data on 162 units, and 702 patients with 1,631 patient-years of follow-up. An agent-based model was designed and programmed on the Netlogo platform to simulate patients and units individually over time. New patients were created based on national disease prevalence statistics. Patients' disease journeys were modelled with a Bath AS Disease Activity Index (BASDAI) score. The model included hospital outpatient attendances, treatment histories, drug costs, and key patient demographics. The baseline simulation was run for two simulated years, repeated 10 times, and assessed against the BSRBR-AS dataset for validation. The model was subsequently used to explore five experimental scenarios in which the time between the date of diagnosis, to first introduction to biologics $(d-b)$ was varied by increasing the number of appointments. The experiment was run 10 times for each parameter setting.

Results: In the baseline model in a typical two year run, 13,631 new patients attended 5,167 baseline, and 6,966 follow-up appointments. Of these, 6,324 and 623 were prescribed $\geq 1 \mathrm{NSAID}$, and biologics, respectively. The validation comparison tests showed a high-level of similarity between simulated output and target datasets. In the target data, $d-b$ was 250 days. In the experimental scenarios, as might be expected, earlier biologic access improved outcomes but at higher-costs (Figure 1; Table 1). Reducing $d-b$ to 150 days doubled the number of patients on biologics at 2 years from 623 to 1,286 . It also led to $8 \%$ more patients achieving a BASDAI of 0 to 2.5 at 2 years, with $5 \%, 1 \%$, and $2 \%$ less patients achieving $2.5-5$, 5 to 7.5 and 7.5 to 10 BASDAl, respectively. Reducing d-b to 150 days increased drug costs from £3.2 million to £8.8 million. However, the total number of appointments (a proxy for staff costs) increased proportionality less from 16,000 to 20,000
Table 1. Influence of varying the time between diagnosis to biologic treatment (d-b) on drug-use and staffing costs

\begin{tabular}{lcccc}
\hline $\begin{array}{l}\text { Diagnosis } \\
\text { to Biologic } \\
(\mathrm{d}-\mathrm{b})\end{array}$ & $\begin{array}{c}\text { Drug Costs } \\
\text { Unit (£k) }\end{array}$ & $\begin{array}{c}\text { Total } \\
\text { Appointments }\end{array}$ & $\begin{array}{c}\text { No. patients } \\
\text { prescribed } \\
\text { NSAIDs }\end{array}$ & $\begin{array}{c}\text { No. patients } \\
\text { prescribed } \\
\text { Biologics }\end{array}$ \\
\hline 150 & 8,796 & 20,384 & 7,154 & 1,283 \\
220 & 5,702 & 18,592 & 6,796 & 971 \\
250 & 3,259 & 16,214 & 6,324 & 621 \\
260 & 2,054 & 14,700 & 5,968 & 382 \\
265 & 1,297 & 13,411 & 5,562 & 233 \\
\hline
\end{tabular}

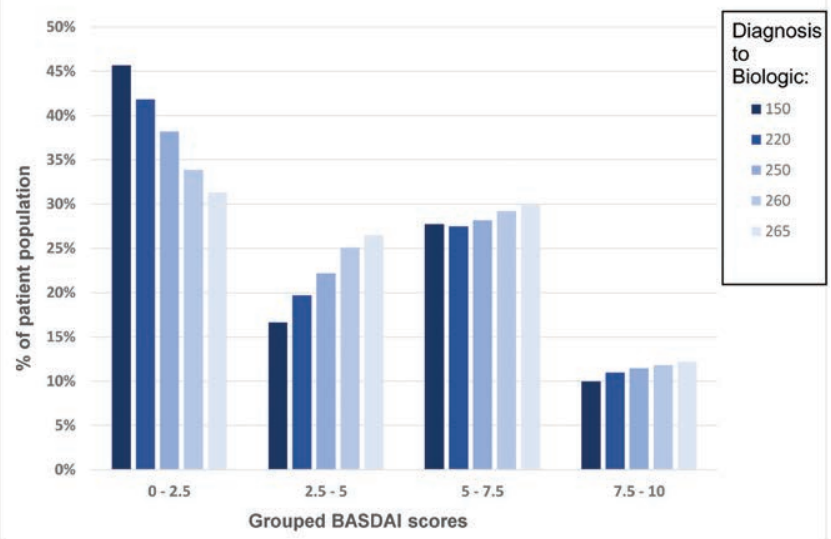

Figure 1. Influence of varying the time between diagnosis to biologic treatment (d-b) on 2 year BASDAI outcome

Conclusion: We have successfully developed, and validated an agent-based approach to model the effect of key policy changes on the whole healthcare system, providing output estimates of cost and patient outcomes, based on integrated real-world data. To our knowledge this is the first attempt to explore the patient journey in people with axSpA in this way. The model provides a useful tool for exploring the effects of changing the way healthcare is delivered to patients with this disease. Our experimental analysis lends support to the case for increasing staffing and drug expenditure to achieve current NICE standards of care in AS.

Acknowledgments: Financial support National Axial Spondyloarthritis Society (NASS), data access BSR.

Disclosure of Interests: Alan Roach Grant/research support from: I was awarded an I-CRP grant from Pfizer for a similar simulation in RA, this was for about £50k and ran from 1/9/15 28/2/17., Ian Scott: None declared, Gary Macfarlane: None declared, Gareth T. Jones Grant/research support from: Pfizer, AbbVie, UCB, Celgene and GSK., Alex MacGregor: None declared DOI: 10.1136/annrheumdis-2020-eular.1507

\section{\begin{tabular}{|l|l}
\hline OP0285 TOWARDS IMPLEMENTING THE OMOP CDM ACROSS \\
\hline
\end{tabular} FIVE EUROPEAN BIOLOGIC REGISTRIES}

E. Burn ${ }^{1}$, L. Kearsley-Fleet ${ }^{2}$, K. Hyrich ${ }^{3}$, M. Schaefer ${ }^{4}$, D. Huschek ${ }^{5}$, A. Strangfeld ${ }^{6}$, J. Zavada ${ }^{6}$, M. Lagová ${ }^{7}$, D. Courvoisier ${ }^{8}$, C. Tellenbach ${ }^{9}$, K. Lauper ${ }^{10}$, C. SánchezPiedra $^{11}$, N. Montero ${ }^{11}$, J. T. Sanchez-Costa ${ }^{11}$, D. Prieto-Alhambra ${ }^{12}$. ${ }^{1}$ University of Oxford, NDORMS, Oxford, United Kingdom; ${ }^{2}$ The University of Manchester, Centre for Epidemiology Versus Arthritis, Manchester, United Kingdom; ${ }^{3}$ The University of Manchester, Manchester Academic Health Science Centre, Centre for Epidemiology Versus Arthritis, Manchester, United Kingdom; ${ }^{4}$ Epidemiology Unit, German Rheumatism Research Center, Berlin, Germany; ${ }^{5}$ Epidemiology Unit, German Rheumatism Research Center, Berlin, Germany; ${ }^{6}$ Institute of Rheumatology, Prague, Czech Republic; ${ }^{7}$ Institute of Biostatistics and Analyses Ltd, Brno, Czech Republic; ${ }^{8}$ Division of Rheumatology, University Hospitals of Geneva, Geneva, Switzerland; ${ }^{9}$ Swiss Clinical Quality Management in Rheumatic Diseases, Zurich, Switzerland; ${ }^{10}$ Centre for Epidemiology Versus Arthritis, The University of Manchester, Manchester Academic Health Science Centre, Manchester, United Kingdom; ${ }^{11}$ Research Unit, Spanish Society of Rheumatology, Madrid, Spain; ${ }^{12}$ University of Oxford, NDORMS, Oxford, United Kingdom

Background: The Observational and Medical Outcomes Partnerships (OMOP) common data model (CDM) provides a framework for standardising health data Objectives: To map national biologic registry data collected from different European countries to the OMOP CDM. 
Methods: Five biologic registries are currently being mapped to the OMOP CDM: 1) the Czech biologics register (ATTRA), 2) Registro Español de Acontecimientos Adversos de Terapias Biológicas en Enfermedades Reumáticas (BIOBADASER), 3) British Society for Rheumatology Biologics Register for Rheumatoid Arthritis (BSRBR-RA), 4) German biologics register 'Rheumatoid arthritis observation of biologic therapy' (RABBIT), and 5) Swiss register 'Swiss Clinical Quality Management in Rheumatic Diseases' (SCQM).

Data collected at baseline are being mapped first. Details that uniquely identify individuals are mapped to the person table, with the observation_period table defining the time a person may have had clinical events recorded. Baseline comorbidities are mapped to the condition_occurrence CDM table, while baseline medications are mapped to the drug_exposure CDM table. This mapping is summarised in Figure 1.

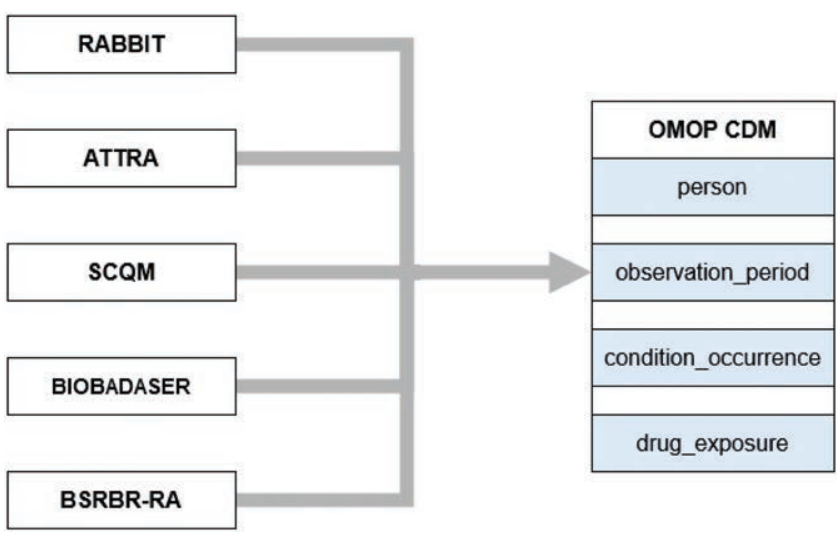

Figure 1. Overview of initial mapping

Results: A total of 64,901 individuals are included in the 5 registries being mapped to the OMOP CDM, see table 1. The number of unique baseline conditions being mapped range from 17 in BSRBR-RA to 108 in RABBIT, while the number of baseline medications range from 26 in ATTRA to 802 in BSRBR-RA. Those registries which captured more comorbidities or medications generally allowed for these to be inputted as free text.

Table 1. Summary of initial code mapping

\begin{tabular}{lccc}
\hline Registry & $\begin{array}{c}\text { Number of } \\
\text { individuals }\end{array}$ & $\begin{array}{c}\text { Number of mapped } \\
\text { baseline conditions }\end{array}$ & $\begin{array}{c}\text { Number of mapped } \\
\text { baseline medications }\end{array}$ \\
\hline ATTRA & 5,326 & 26 & 26 \\
BIOBADASER & 6,496 & 30 & 51 \\
BSRBR-RA & 21,695 & 17 & 802 \\
RABBIT & 13,062 & 108 & 78 \\
SCQM & 18,322 & 26 & 33 \\
\hline
\end{tabular}

Conclusion: Due to differences in study design and data capture, the baseline information captured on comorbidities and drugs across registries varies greatly. However, these data have been mapped and mapping biologic registry data to the OMOP CDM is feasible. The adoption of the OMOP CDM will facilitate collaboration across registries and allow for multi-database studies which include data from both biologic registries and other sources of health data which have been mapped to the CDM.

Disclosure of Interests: Edward Burn: None declared, Lianne Kearsley-Fleet: None declared, Kimme Hyrich Grant/research support from: Pfizer, UCB, BMS, Speakers bureau: Abbvie, Martin Schaefer: None declared, Doreen Huschek: None declared, Anja Strangfeld Speakers bureau: AbbVie, BMS, Pfizer, Roche, Sanofi-Aventis, Jakub Zavada Speakers bureau: Abbvie, UCB, Sanofi, Elli-Lilly, Novartis, Zentiva, Accord, Markéta Lagová: None declared, Delphine Courvoisier: None declared, Christoph Tellenbach: None declared, Kim Lauper: None declared, Carlos Sánchez-Piedra: None declared, Nuria Montero: None declared, Jesús-Tomás Sanchez-Costa: None declared, Daniel Prieto-Alhambra Grant/research support from: Professor Prieto-Alhambra has received research Grants from AMGEN, UCB Biopharma and Les Laboratoires Servier, Consultant of: DPA's department has received fees for consultancy services from UCB Biopharma, Speakers bureau: DPA's department has received fees for speaker and advisory board membership services from Amgen

DOI: 10.1136/annrheumdis-2020-eular.3303

\section{Novel diagnostic and therapeutic approaches in paediatric rheumatic diseases.}

\section{OP0286 PROTEOMICS AND RNA SEQUENCING APPROACHES HIGHLIGHT THE ROLE OF ENDOTHELIAL CELL DYSREGULATION IN IL-1 AND IFN MEDIATED AUTOINFLAMMATORY DISEASES, NOMID AND CANDLE}

S. Alehashemi ${ }^{1}$, M. Garg ${ }^{1}$, B. Sellers ${ }^{1}$, A. De Jesus ${ }^{1}$, A. Biancotto ${ }^{1}$, J. Lack ${ }^{1}$, R. Goldbach-Mansky ${ }^{1}{ }^{1}$ National Institutes of Health, Bethesda, United States of America

Background: Systemic Autoinflammatory diseases present with sterile inflammation. NOMID (Neonatal-Onset Multisystem Inflammatory Disease) is caused by gain-of-function mutations in NLRP3 and excess IL-1 production, presents with fever, neutrophilic dermatosis, aseptic meningitis, hearing loss and eye inflammation; CANDLE (Chronic Atypical Neutrophilic Dermatosis, Lipodystrophy and Elevated Temperature) is caused by loss-of-function mutations in proteasome genes that lead to type- 1 interferon signaling, characterized by fever, panniculitis, lipodystrophy, cytopenia, systemic and pulmonary hypertension and basal ganglia calcification. IL-1 blockers are approved for NOMID and JAK-inhibitors show efficacy in CANDLE treatment.

Objectives: We used proteomic analysis to compare differentially expressed proteins in active NOMID and CANDLE compared to healthy controls before and after treatment, and whole blood bulk RNA seq to identify the immune cell signatures.

Methods: Serum samples from active NOMID $(n=12)$ and CANDLE $(n=7)$ before and after treatment (table 1) and age matched healthy controls $(\mathrm{HC})(n=7)$ were profiled using the SomaLogic platform ( $n=1125$ proteins). Differentially expressed proteins in NOMID and CANDLE were ranked after non-parametric tests for unpaired (NOMID $p<0.05$, CANDLE, $p<0.1)$ and paired $(p<0.05)$ analysis and assessed by enriched Gene Ontology pathways and network visualization. Whole blood RNA seq was performed (NOMID $=7, \mathrm{CANDLE}=7$, Controls $=5$ ) and RPKM values were used to assess immune cells signatures.

Results: Compared to control, 205 proteins (127 upregulated, 78 downregulated) were significantly different at baseline in NOMID, compared to 163 proteins (101 upregulated, and 62 downregulated) in CANDLE. 134 dysregulated proteins (85 upregulated, 49 downregulated) overlapped in NOMID and CANDLE (Figure 1). Pathway analysis identified neutrophil and monocyte chemotaxis signature in both NOMID and CANDLE. NOMID patients had neutrophilia and active neutrophils. CANDLE patients exhibited active neutrophils in whole blood RNA. Endothelial cell activation was the most prominent non-hematopoietic signature and suggest distinct endothelial cell dysregulation in NOMID and CANDLE. In NOMID, the signature included neutrophil transmigration (SELE) endothelial cell motility in response to angiogenesis (HGF, VEGF), while in CANDLE the endothelial signatures included extracellular matrix protein deposition (COL8A) suggesting increased vascular stiffness. CANDLE patients had higher expression of Renin, 4 out of 7 had hypertension, NOMID patients did not have hypertension. Treatment with anakinra and baricitinib normalized 143 and 142 of dysregulated proteins in NOMID and CANDLE respectively.

Conclusion: Differentially expressed proteins in NOMID and CANDLE are consistent with innate immune cell activation. Distinct endothelial cell signatures in NOMID and CANDLE may provide mechanistic insight into differences in vascular phenotypes. Treatment with anakinra and Baricitinib in NOMID and CANDLE leaves $30 \%$ and $13 \%$ of the dysregulated proteins unchanged.

Table 1. Patient's characteristics

\begin{tabular}{|c|c|c|c|c|}
\hline & \multicolumn{2}{|c|}{$\begin{array}{c}\text { NOMID } \\
\mathrm{N}=12, \text { Male }=6\end{array}$} & \multicolumn{2}{|c|}{$\begin{array}{c}\text { CANDLE } \\
\mathrm{N}=7, \text { Male }=6\end{array}$} \\
\hline Age & \multicolumn{2}{|c|}{$12(2,28)$} & \multicolumn{2}{|c|}{$16(3,20)$} \\
\hline Ethnicity & \multicolumn{2}{|c|}{$80(20)$} & \multicolumn{2}{|c|}{$100(30)$} \\
\hline \multirow[t]{2}{*}{ Genetics } & \multicolumn{2}{|c|}{$\begin{array}{l}\text { NLRP3 mutation } \\
\text { (2 Somatic, } 10 \text { Germline) }\end{array}$} & \multicolumn{2}{|c|}{$\begin{array}{l}\text { mutations in proteasome compo } \\
\text { nent genes } \\
\text { ( } 1 \text { digenic, } 6 \text { Homozygous/com- } \\
\text { pound Heterozygous) }\end{array}$} \\
\hline & $\begin{array}{l}\text { Before } \\
\text { treatment }\end{array}$ & $\begin{array}{c}\text { After } \\
\text { treatment }\end{array}$ & $\begin{array}{c}\text { Before } \\
\text { treatment }\end{array}$ & $\begin{array}{c}\text { After } \\
\text { treatment }\end{array}$ \\
\hline $\begin{array}{l}\text { CRP } \\
\text { Median (range) } \mathrm{mg} / \mathrm{L}\end{array}$ & $52(16-110)$ & $5(0-23)$ & $5(0-101)$ & $1(0-4)$ \\
\hline $\begin{array}{l}\text { IFN score } \\
\text { median (range) }\end{array}$ & 0 & NA & 328 (211-1135) & $3(0-548)$ \\
\hline
\end{tabular}

